\title{
Precarious work and labor market segmentation: a comparative study on mainland China and Hong Kong
}

Jun Li

\author{
Correspondence: ccsolj@126.com \\ Institute of Sociology, Shanghai \\ Academy of Social Sciences, No. 7, \\ Lane 622, Middle Huaihai Road, \\ Shanghai, China
}

\begin{abstract}
The world-wide growth of precarious work has created a new type of labor market segmentation and calls for cross-society comparison study. Mainland China and Hong Kong facilitate such a comparison, since the two societies operated in quite different socioeconomic institutions have experienced the same change of employment relations. By analyzing two representative and comparable survey data, this research has found similarity as well as discrepancy regarding occurrence and segmentation of precarious work in the two labor markets. In general, precarious work distributes in more economic sectors in mainland China than it does in Hong Kong, while it engenders less segmentation in the former labor market. This is closely related to the institutional and practical differences in labor market regulation of the two societies.

Keywords: Precarious work, Labor market segmentation, Mainland China, Hong Kong
\end{abstract}

\section{Introduction}

The labor market segmentation theory was developed amidst debates with the neoclassical theory of the labor market (Ge 2000; Yao and Li 2005). The latter conceives the labor market as a unified, competitive market: market mechanisms determine the allocation of labor and wage levels, and an equilibrium is eventually achieved. On the contrary, the labor market segmentation theory views the labor market to be segmented by institutional, societal, and structural factors: a perfectly unified or competitive labor market does not exist, and inter-sectoral mobility is limited.

Doeringer and Piore (1971) proposed the idea of "dual labor market segmentation", which was the earliest and the most representative perspective in the labor market segmentation theory. They viewed the labor market as segmented into a primary and a secondary market. A number of contrasts exist between these two segments-the primary labor market is usually characterized by higher wages, better working conditions, more promotion opportunities, a well-regulated administrative system and a higherlevel of job security, whereas the secondary labor market is usually characterized by low wages, bad working conditions, a lack of promotion opportunities, high turnover rates, etc. Later research has focused on the principles that determine labor market segmentation: the labor market can be segmented based on a variety of factors,

(c) The Author(s). 2019 Open Access This article is distributed under the terms of the Creative Commons Attribution 4.0 International License (http://creativecommons.org/licenses/by/4.0/), which permits unrestricted use, distribution, and reproduction in any medium, provided you give appropriate credit to the original author(s) and the source, provide a link to the Creative Commons license, and indicate if changes were made. 
including occupational closure, industrial structure and monopoly, organizational structure and organizational modes (see Li 2016).

A major change in the global labor market since the end of the twentieth century has been the expansion of nonstandard labor relations and precarious work. Some scholars have noticed that the division between standard and nonstandard employment can create a division of "insiders-outsiders" in the organizational structure of a company, and this micro-level segmentation can further lead to a labor market segmentation at the macro level (Atkinson 1984, 1987; Kalleberg 2003). Empirical research on this subject has been carried out in a number of different social contexts, including China. That being said, there is a lack of comparative research on the impacts of nonstandard labor relations across different economic, political and institutional contexts. Against the backdrop of globalization, both mainland China and Hong Kong have seen a rapid expansion of nonstandard labor relations and precarious work. Yet, a key difference between the two societies consists of the "one country, two system" regime, which can be taken as a natural experiment. This article will compare the cases of mainland China and Hong Kong, to address this gap in existing literature.

\section{Precarious work and labor market segmentation}

The expansion of flexible employment, nonstandard employment relations and precarious work is an important global phenomenon that has taken place since the end of the twentieth century. ${ }^{1}$ In the Post-WWII golden age of capitalism, standard, typical and stable labor relations predominated, characterized by long-term and standard employment, fixed work hours and places of work, heavy restrictions against layoffs, and the social security and welfare that workers enjoyed. After the economic crisis of the late 1970s and 1980s, however, there has been a growing request for flexible work arrangements in developed countries, and this practice has become increasingly common. Meanwhile, in developing countries, flexible employment is also viewed as an important approach to stimulate job creation. In this context, nonstandard labor relations and precarious work have expanded all over the world.

In academia, the concept of flexible employment was first used in management science to depict a series of arrangements and measures in human resource management. Atkinson (1984) was the first to construct a typology of labor flexibility: (1) numerical flexibility: companies adjust the size of their workforce in response to the changing demand for labor; (2) functional flexibility: companies increase the efficiency of their workforce by improving the division of labor, diversifying the technologies they use and creating a multi-skilled workforce; (3) temporal flexibility: companies implement flexible work schedules and labor contract terms, in order to quickly adapt to market changes and improve productivity; (4) financial flexibility: companies adopt a flexible manner of remunerating their workforce; payment can be made on an hourly, daily, weekly, monthly or annual basis, and employers expect to be able to adjust pay costs through the flexibility of wage payment systems. Meanwhile, nonstandard employment relations are also heterogeneous. In Kalleberg's review article, nonstandard work arrangements include part-time work, temporary work and contract work; each can be

${ }^{1}$ These three concepts are widely used in the literature. They are interrelated but are also different from each other. The empirical section of this article focuses on precarious work, but the literature review discusses the common aspects of the three concepts. 
further classified into subgroups (Kalleberg 2000). O'Connor (2013) categorized nonstandard employment in EU countries into part-time work, temporary work, labor dispatch, self-employment, etc. In one way or another, the aforementioned examples of labor relations deviate from the standard employment relations of the past.

The three parties in the labor market - namely companies, workers and the government-contribute to the emergence of flexible/nonstandard employment. First and foremost, companies adopt labor flexibility to reduce organizational costs and to better respond to the rapidly-changing market environment, as illustrated in the four types of flexibility mentioned above. Second, workers have also changed their viewpoints and preferences, which is sometimes cited to legitimize nonstandard employment. Third, labor market deregulation is another important factor. For example, labor dispatching was firmly outlawed in many countries in the past. Yet, this ban was gradually removed, and the Private Employment Agencies Convention established by the International Labor Organization obviously promoted this trend (Li 2011; Tian 2014). Historically, labor laws in Western industrialized countries followed a trajectory of "autonomyregulation-deregulation," where, in general, a pendulum effect can be observed in their labor relations practices (Kalleberg 2009; Polanyi 1944).

In many countries, the expansion of flexible employment and nonstandard labor relations is problematic, as it has increased job insecurity. Supporters highlight the positive effects of labor flexibility on business and economic development, whereas opponents point out its negative impacts on workers and blame it for phenomena such as "working poor" and the "new poor" (see Xiong 2015). This debate has generated a large amount of empirical research among scholars abroad, who thus put forward the "new labor market segmentation" proposition. It is labeled as "new," because previous research on labor market segmentation tended to focus on other forms of segmentation, such as those based on occupations, economic sectors and organizational structures (see Baron and Bielby 1980; Kalleberg and Sorensen 1979).

The first scholar who proposed the "new segmentation" proposition was Atkinson (1984, 1987). Other scholars further developed this perspective. Atkinson examined the measures that British companies adopted to promote labor flexibility. These measures largely transformed the traditional organizational structure of a company, so that the division between white-collar and blue-collar workers became less relevant. According to Atkinson, the division that became increasingly relevant was whether a particular line of work was specific to a company, or if it only involved general skills. The former group includes production management and maintenance occupations, while the latter includes system analysts and shuttle drivers. Both groups exist at all levels in a company. Based on this new break-up, companies can apply different employment policies for different employees, which creates a "core-periphery" structure. Employees of the core group engage in the key tasks of the company, and they are more valued and better protected. By contrast, employees of the peripheral group undertake general and replaceable jobs, and a company can easily expand or reduce this workforce in response to the dynamics of the market. Harrison (1994) observed a similar division in the US workforce: full-time employees enjoy job security, benefits, and training and promotion opportunities, in contrast to informal employees. Kalleberg (2003) further pointed out that the separation between standard and nonstandard workers leads to a distinction between organizational "insiders" and "outsiders," and as a consequence new forms of 
segmentation emerge in the labor market. In sum, the new segmentation theory follows Doeringer and Piore's framework, but it has an emphasis on the new factors that create labor market segmentation (Hudson 2007).

Of course, in empirical research, scholars do not restrict themselves to studying the workforce segmentation within a single company. Rather, they have gone beyond to study the labor market in general terms and how it is affected by the expansion of nonstandard/ precarious work. These studies cluster around the following two main themes.

The first theme concerns the impacts of precarious work on workers' salaries and job quality. Kalleberg and his colleagues (2000) first examined the relationship between precarious work and job characteristics. After controlling for individual characteristics, household status, economic sectors and occupational categories, precarious work is still significantly related to "bad" jobs. Here, nonstandard workers include on-call workers, day laborers, contracted laborers, outsourced laborers and part-time workers; "bad" jobs are characterized by low wages and a lack of benefits (such as pensions and health insurance). McGovern and others (2004) reached similar conclusions for Britain, although they only included part-time work, temporary work and fixed-term work as precarious work. The negative effect of fixed-term contracts on salary was also identified in France and Germany, which, according to Gash and McGinnity (2007), created "new forms of inequality" in Europe. Giesecke (2009) further found that the negative impacts of atypical employment relations on wages and unemployment are rather uneven: they are more significant for fixed-term and contract workers than for part-time workers.

The other research theme asks whether precarious work is a bridge or a trap for workers-in other words, whether it enables workers to move up towards standard work in the primary job market or whether it condemns workers to unemployment or the secondary labor market. Jacobs and Qian (1997) studied part-time employees' career mobility in the US. They found that $60 \%$ of them remained in the same type of job after 1 year and that their chance of entering a full-time job was lower than that of quitting the job market entirely. Drawing on fieldwork and questionnaires, Pedulla (2016) found that working part-time jobs has negative impacts on the chance of successfully securing full-time work, particularly for male workers. Giesecke and Groß's (2003) research on the work history of laborers in Germany agrees in that temporary work and fixed-term work increase the risk of stagnating in precarious work or unemployment in the future. The authors conclude that short-term or fixed-term contracts form a secondary labor market, and labor flexibility deepens labor market segmentation. Finally, Mansson and Ottosson's (2011) research in Switzerland also rejects the "bridge" argument, as they find the chance of a part-time worker finding a full-time job to be low. Nevertheless, some empirical evidence seems to support the "bridge" argument (Gash 2008; McGinnity et al. 2005; Steijn et al. 2006). This suggests that more research is needed to advance our understanding on this issue.

\section{Existing literature on precarious work in Mainland China and Hong Kong}

Literature review reveals that, in tandem with the global expansion of the phenomenon of precarious work, research has been conducted on whether it has created new forms of labor market segmentation. Scholars have already studied cases in the USA, UK and the European continent, and recently, they also started paying attention to Asia. In 
2013, American Behavioral Scientist published two special issues presenting the situation of precarious work in ten Asian countries and regions, including Japan, South Korea and China (Kalleberg and Hewison 2013). But these essays do not include any empirical research on whether new forms of labor market segmentation have occurred in Asia. In his review article, Kalleberg (2000) called for cross-societal comparative research to examine how economic, political and institutional factors mediate the impacts of nonstandard labor relations in different social contexts. However, little has been done since then.

From this viewpoint, it is unfortunate that Hong Kong was not included in this series of research on Asia. Hong Kong is recognized as one of the "freest" economies in the world. Following its long tradition of liberal capitalism, its authorities rarely intervene in market activities, including the labor market. On the contrary, as a socialist polity, mainland China implemented a new Labor Law in 2008, which is widely considered as pro-labor and anti-capitalist. In recent years, despite the "one country, two systems" regime, precarious work has expanded quickly in both societies as a part of the process of globalization. According to official statistics, in Hong Kong, the incidence rates of self-employment and part-time work have increased steadily since the mid-1990s (see Fig. 1). In mainland China, the weight of self-employment and "other forms of employment" also started to rise in the mid-1990s (see Fig. 2). Here, the category "other forms of employment" refers to the gap between the total number of jobs and the sum of jobs in all the other employment categories. Cai and his colleagues (Cai 2004; Park and Cai 2011) implied that the category "other forms of employment" actually coincides with informal jobs. ${ }^{2}$ Some scholars pointed out that an overall informalization of the labor market occurred in mainland China during state enterprise restructuring and the collapse of the previous social contract (Friedman and Lee 2010). This is consistent with

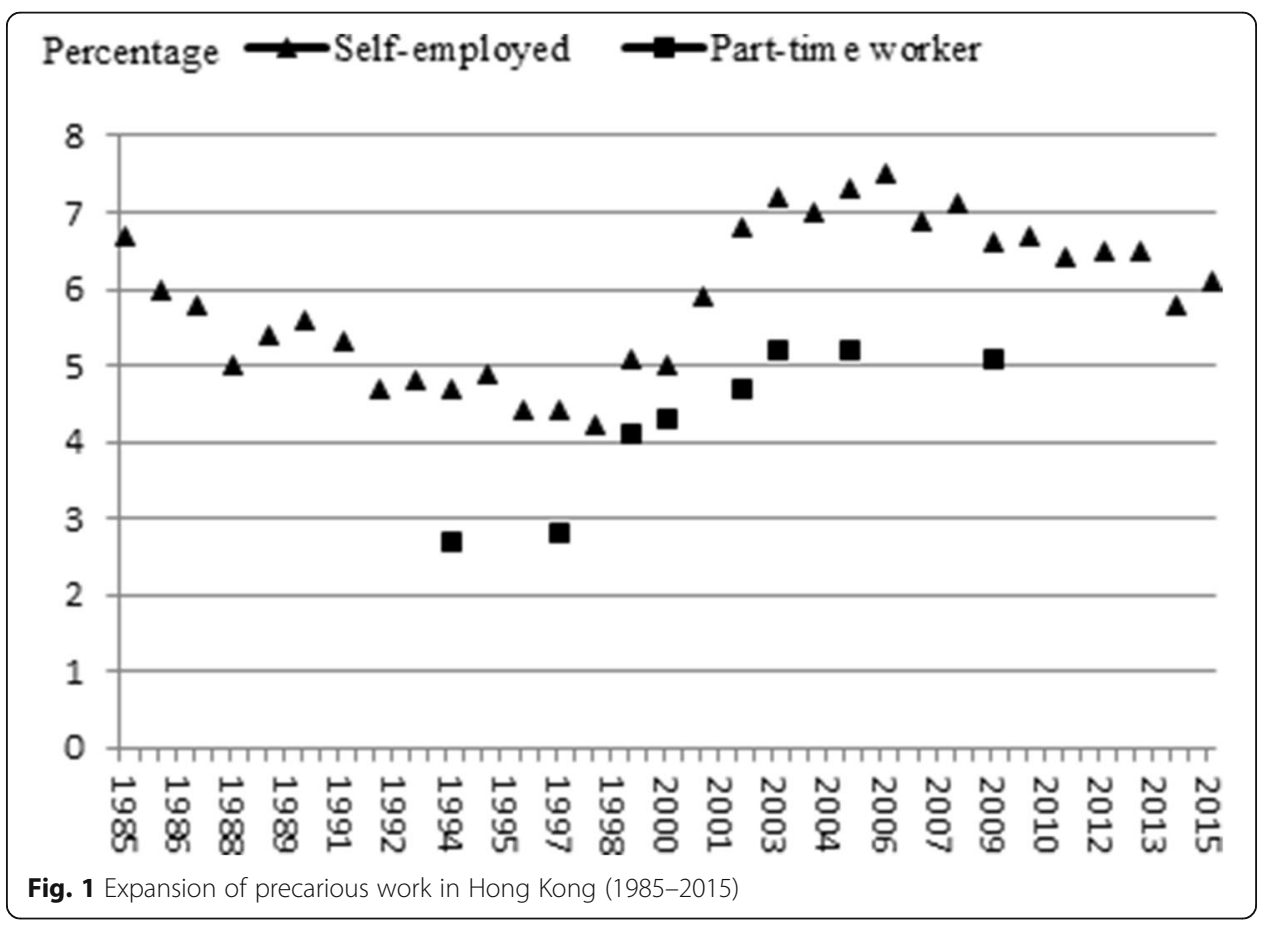




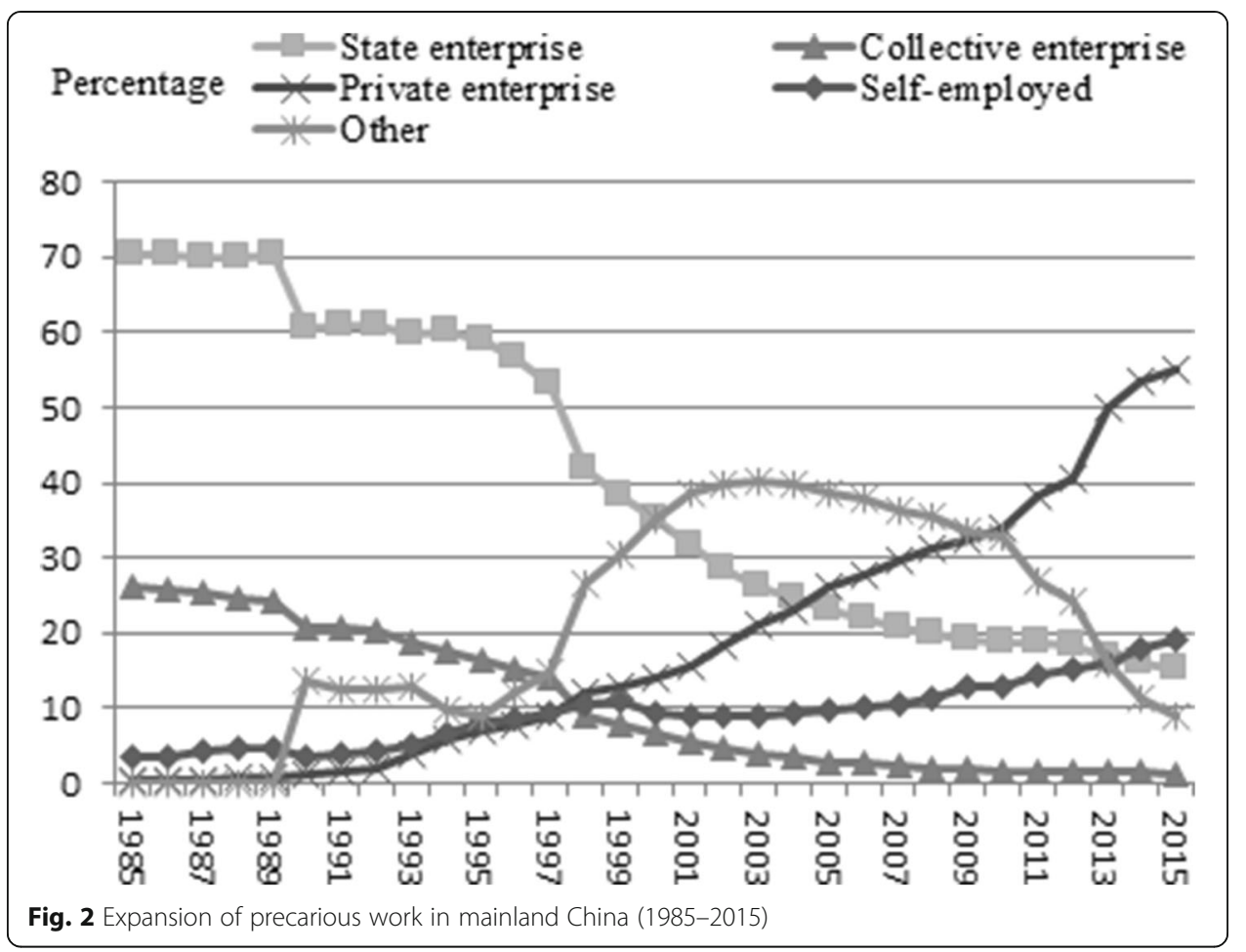

other authors' observation of industries that have been "informalized," such as the automobile industry and construction (Swider 2015; Zhang 2011).

Mainland China and Hong Kong represent two ideal subjects for cross-societal comparative research. This article asks the following questions. Regarding whether precarious work has created new forms of labor market segmentation and have the differences in social and economic systems in the two regions led to different outcomes? Of course, an oversimplification of the differences of the two cases as "capitalism versus socialism" should be avoided. Rather, it is necessary to analyze the circumstances of labor market regulation in these two societies and how they have affected nonstandard workers. Some pilot research has been conducted on this issue.

Existing literature on Hong Kong focuses on the characteristics of precarious/nonstandard employment, its trend of expansion, and its social and economic roots. Chiu and his colleagues (Chiu et al. 2008) depicted the trend of flexible employment in Hong Kong: while it has always been an important employment type in Hong Kong, its weight further increased after the 1997 Asian Financial Crisis. This was driven by employers' demands for reducing costs, which can be explained by institutional factors such as Hong Kong's colonial tradition, minimal government intervention in labor relations and the underdevelopment of a labor movement. Wong (2001) explored from the employers' perspective the reason why companies in Hong Kong increasingly hired

\footnotetext{
${ }^{2}$ Before 1990, the total employed population in urban areas was counted by adding up the number of people working in work units and the number of people registered to work in private companies. After 1990, the total employed population in urban areas was calculated based on the results of the household surveys of the urban labor force. The method of data collection after 1990 was more accurate, but a gap exists between the statistics obtained before and after the new method was adopted. The data for the years after 2001 have been revised according to the sixth Census. It is possibly for this reason that the weight of the category "other types of employment" in Fig. 2 declines around this period.
} 
temporary workers. Her interviews with four companies revealed that, while this practice was partly driven by motivations such as reducing costs and increasing flexibility, it could also be possible that local employers were just following the international trend. Ngo (2002) pointed out that, unlike the European experience, part-time work in Hong Kong was not much of a "gender phenomenon." Its expansion in Hong Kong can be attributed to the employer strategy of reducing costs and increasing flexibility at the micro level, as well as to liberal economic policy at the macro level. Though Ngo questioned whether part-time work consisted of a secondary labor market and whether there was salary discrimination against part-time workers, Lee and Wong (2004) argued that workers in Hong Kong had been marginalized due to de-industrialization, the introduction of automation technology and migrant labor, as well as deregulation; the labor market in Hong Kong was stratified into three segments, in which nonstandard labor was found at the lowest segment. There has been no consensus, however, on whether nonstandard, precarious work has generated a new form of labor market segmentation in Hong Kong.

Research on precarious work in mainland China can be roughly divided into three groups. The first group reviews the phenomenon of precarious work in China in general terms, including its definition, size, problems, causes and possible consequences (Peng and Yao 2004; Wu and Cai 2006). The second group references the labor codes on atypical labor relations in other countries in order to generate policy recommendations for policy makers in China (Dong 2007; Tian 2014). The third group, drawing on quantitative methods, studies the relationship between informal/precarious work and wage inequality.

In the last group of research, Luo (2008) and Wu (2009) conducted preliminary studies on job stability and informal employment. Both found that, after controlling for individual characteristics, the rates of return on human capital are not low for precarious/informal workers compared to formal employees, although the former earn significantly lower wages. Based on data from the same and other sources, however, this new form of labor market segmentation not only exists, but is also expanding. For example, using data from the 2005 mini-Census, Xue and Gao (2012) found that formal employees not only enjoyed higher incomes, but also higher rates of return on human capital. Based on data from the 1997-2006 China Health and Nutrition Survey (CHNS), Chang and Wang (2010), as well as $\mathrm{Qu}(2011)$, identified an expanding wage gap between the formal and the informal sectors. Chang and Wang (2010) also identified an expanding gap in the rates of return on education and work experience between formal and informal workers. According to the data from a 2009 survey, formal employees have higher average rates of return on education than precarious workers. Moreover, the advantage formal employees enjoy holds for all income quantiles (Wei and Yu 2012). Some scholars went beyond the formal-informal dichotomy and examined income inequality among various employment types. For example, Qu (2012) classified workers into formal workers, informal workers and selfemployed workers; Li and Zhao (2016) classified employment contracts into life-long contracts, long-term contracts, short-term contracts and non-contracts. Their research proved the segmenting effects of employment type on wages. Other scholars also included migrant workers or the floating population in their analysis. They found that even in this population, precarious work can lead to significant income loss or wage discrimination (Huang 2009; Kou and Liu 2013; Yang 2015). 
Although researchers in both mainland China and Hong Kong tend to recognize the existence of labor market segmentation based on precarious work, the two societies largely differ from each other in how their labor markets are regulated. Hong Kong's Employment Ordinance only establishes labor rights for workers with continuous contracts $^{3}$ (including holidays, paid annual leave, paid sick days, severance payments and long service payments), but does not protect the rights of flexible/nonstandard workers (Lee and Wong 2004). For example, most of the protections that formal employees enjoy do not apply to part-time workers, except for the mandatory provident fund they can obtain after working for an employer for 60 consecutive days (Wong 2001). The Minimum Wage Ordinance was not passed in Hong Kong until 2010. Given this context, employers have an incentive to hire nonstandard labor to evade the protections and benefits they are obliged to offer to their formal employees. For example, self-employment in Hong Kong increased after the implementation of the mandatory provident fund scheme in 2000, because this allows employers to avoid their obligation to contribute to the fund on behalf of their formal employees (Chiu et al. 2008).

In mainland China, labor legislation has gone through a trajectory of "regulation-autonomy-regulation - a combination of regulation and deregulation." On the one hand, the eligibility for open-ended work contracts was widened, which signaled a tightening of labor law. On the other hand, dispatch work and part-time work were legalized, which was interpreted as a deregulation of the labor market (Tian 2014: 23-24). In response, however, to the serious repercussions that the new Labor Law generated in society, the government implemented harsher regulations over atypical employment, as embodied in the modification of the Labor Contract Law in 2012, as well as the implementation of the Interim Provisions on Dispatch Work and the Measures for the Implementation of Administrative License for Dispatch Labor in 2013. These last two laws were aimed at reinforcing the regulation of dispatch work. Even when flexible employment was promoted around the year 2000 to stimulate job creation in response to the mass layoffs caused by state enterprise restructuring, the government established policies and regulations for part-time workers and temporary workers on issues such as health insurance, labor relations, wages, and social security (Tian 2014: 67-68).

Based on the differences mentioned above, the core hypothesis proposed in this article is: precarious workers in Hong Kong will face deeper labor market segmentation than their counterparts in mainland China. As discussed in our literature review, the key to test or measure labor market segmentation is whether wages and labor force allocation are determined by different mechanisms in different sectors. More specifically, two empirical studies are needed. The first one will examine inter-sectoral wage inequality: if workers with the same amount of human capital expect different wage levels in different sectors, then the labor market is segmented. The second one will examine the return on human capital (measured in years of schooling): if the return on human capital varies across sectors and is lower in the secondary labor market, then the labor market is segmented (Yuan 2008; Li 2016). In sum, the key test used in this research to determine whether labor market segmentation exists is whether wages and the return on human capital are significantly different between formal employment and precarious

${ }^{3} \mathrm{~A}$ "continuous contract" refers to being employed by the same employer for more than 4 weeks, during which the employee works at least $18 \mathrm{~h}$ per week. 
work. Moreover, a comparison of the size of that difference between mainland China and Hong Kong will inform us about the varying degree of labor market segmentation in these two labor markets.

\section{Data, variables and models}

For mainland China, this research uses data from the 2012 China Labor Force Dynamics Survey (CLDS $)^{4}$ from the Center for Social Survey in Sun Yat-Sen University (in which only samples from urban areas are used) and data from the 2017 Shanghai Urban Neighborhood Survey (SUNS) ${ }^{5}$ from the Center for Data and Urban Science in Shanghai University (in which only household survey data are used). For Hong Kong, this research uses data from the 2011-2012 Hong Kong Panel Study of Social Dynamics (HKPSSD) ${ }^{6}$ provided by the Center for Applied Social and Economic Research in Hong Kong University of Science and Technology. The two surveys, CLDS and HKPSSD, were conducted at roughly the same time period. Both of them use probability sampling, and the samples are representative of the workforces in mainland China and Hong Kong. Moreover, both surveys use similar criteria to define precarious work. Thus, these two surveys fit well for the purpose of cross-societal comparison.

For the CLDS data, precarious work is defined by whether one respondent falls into any of the following categories: (1) self-employed, including non-skilled self-employed workers and non-entrepreneurs, such as casual workers, street venders, hourly workers, self-employed drivers, scavengers, shoe-shiners/shoe repairmen, car wash workers, and street artists, (2) part-time workers and (3) workers with no fixed employer. ${ }^{7}$ For the HKPSSD data, precarious work is defined by whether one respondent falls into one of the following groups: (1) self-employed (vendors) or outworkers, (2) part-time workers and (3) short-term workers or casual workers. The definition of precarious work used in these two surveys is to a large extent similar. Precarious work is the key independent variable in this research, a dummy coding with 1 for precarious work.

That being said, the CLDS is a national survey. Even in this research only its urban section is used, and a control variable "province" is added in the models. Thus, comparability concerns remain. For this reason, two supplementary analyses are conducted. First, a subsample of major cities in mainland China from the CLDS data is used to make a comparison with the HKPSSD data. Second, the SUNS data, which are based in Shanghai, are used to make a comparison with the HKPSSD data. It is reasonable to compare Shanghai and Hong Kong, as Shanghai is the most advanced city in mainland China in terms of economic development, representing the highest level of urbanization, modernization and globalization in the region. If the three comparisons mentioned above reach consistent conclusions, then the difference between mainland China and Hong Kong is robust. A caveat should be noted here if the SUNS data are used. First, SUNS was conducted at a later stage than CLDS and HKPSSD. Second, its

\footnotetext{
${ }^{4}$ For CLDS details, please refer to Center for Social Survey in Sun Yat-Sen University (2013).

${ }^{5}$ For SUNS details, please refer to Sun (2018).

${ }^{6}$ For HKPSSD details, please refer to Wu (2014).

${ }^{7}$ The author also attempted to add other criteria to define precarious work, including the way in which wages are calculated and types of employment contracts. This did not alter the main conclusions. As they are not included in the HKPSSD data, and in order to maintain consistency and comparability between the two data sets, these criteria are not used for the definition of precarious work.
} 
definition of precarious work only includes self-employed manual workers and parttime workers, which differs from the other two surveys.

The fourth comparison, which is more important, compares the CLDS data with the SUNS data. This comparison can further support the key hypothesis of this research, i.e., institutional differences are the key reason why precarious workers in Hong Kong face deeper labor market segmentation than their peers in mainland China. If this is true, as Shanghai and the rest of mainland China are in the same institutional context, it can be expected that the CLDS and the SUNS data will reach similar results.

The dependent variable in this research is monthly salary (log-transformed). The independent variables include years of education, sex, age, occupation, industry, economic sector (private versus public), hukou status and hours of work. These variables are available for both mainland China and Hong Kong.

To examine the wage gap caused by labor market segmentation, this research uses OLS regression and propensity score analysis. OLS regression can examine whether nonstandard workers are paid significantly less than formal employees, after controlling for other variables. The estimation of the relationship between precarious work and wages can be biased, however, if omitted variables bias occurs (in other words, undertaking precarious work can be the result of self-selection). A propensity score analysis is used to address this issue (Guo and Fraser 2010) by matching nonstandard workers with formal employees according to the propensity score of engaging in precarious work. The difference between the two groups after being matched is the treatment or the "causal" effect of engaging in precarious work.

To examine the gap in the return on education caused by labor market segmentation, this research uses OLS regression and switching regression models. OLS regression tests whether the interaction term of the "years of schooling" and "precarious work" variables is statistically significant. In this way, we can know whether a significant difference exists in the return on education (measured as the effect of years of schooling on wages) between formal employees and nonstandard workers. Similarly, OLS estimates can be biased because undertaking precarious work can be the result of selfselection. A switching regression model is used to tackle this issue (Sakamoto and Chen 1991a, Sakamoto 1991b). Three models are produced, one estimating the choice of precarious work, one estimating the determination of incomes earned from precarious work, and one estimating the determination of incomes earned from formal work. Together, these three equations can produce a more precise estimate.

\section{Empirical results}

Table 1 shows the distribution of precarious work in the labor market in mainland China and Hong Kong. The table reports data from both the original samples and the analytical samples. As these two samples show roughly the same patterns, the following discussion will be based solely on the analytical samples.

A big contrast exists between mainland China and Hong Kong in terms of the age, education, occupation and economic sector of precarious workers. In short, precarious work is more dispersed throughout mainland China. Taking education as an example, precarious workers in mainland China are distributed quite evenly across almost all education levels, and $20.42 \%$ of them have an associate's degree or higher. By contrast, 
Table 1 Distribution of precarious work in mainland China and Hong Kong (\%)

\begin{tabular}{|c|c|c|c|c|}
\hline & \multicolumn{2}{|c|}{ Mainland China } & \multicolumn{2}{|l|}{ Hong Kong } \\
\hline & $\begin{array}{l}\text { Original } \\
\text { sample } \\
(N=348+)\end{array}$ & $\begin{array}{l}\text { Analytical } \\
\text { sample } \\
(N=333)\end{array}$ & $\begin{array}{l}\text { Original } \\
\text { sample } \\
(N=565+)\end{array}$ & $\begin{array}{l}\text { Analytical } \\
\text { sample } \\
(N=515)\end{array}$ \\
\hline \multicolumn{5}{|l|}{ Age } \\
\hline$<30$ & 17.85 & 18.02 & 19.83 & 20.19 \\
\hline $30+$ & 24.67 & 25.23 & 14.58 & 14.56 \\
\hline $40+$ & 35.17 & 35.14 & 25.08 & 25.05 \\
\hline $50+$ & 17.32 & 16.52 & 29.83 & 29.90 \\
\hline$>=60$ & 4.99 & 5.11 & 10.68 & 10.29 \\
\hline \multicolumn{5}{|l|}{ Education } \\
\hline Primary school or lower & 17.06 & 17.72 & 30.85 & 29.71 \\
\hline Middle school & 35.70 & 35.74 & 31.36 & 32.23 \\
\hline High school & 27.03 & 26.13 & 29.66 & 30.10 \\
\hline Associate degree & 8.66 & 8.71 & 3.73 & 3.69 \\
\hline College degree or higher & 11.55 & 11.71 & 4.41 & 4.27 \\
\hline \multicolumn{5}{|l|}{ Occupation } \\
\hline Manager/director & 7.09 & 7.21 & 1.19 & 0.78 \\
\hline Professional/technician & 27.82 & 28.53 & 5.61 & 5.24 \\
\hline Administrative staff & 10.50 & 10.81 & 5.77 & 6.41 \\
\hline Sales and service staff & 18.64 & 19.52 & 33.45 & 34.95 \\
\hline Production staff & 16.80 & 17.41 & 19.86 & 19.80 \\
\hline Non-skilled labor and other & 19.16 & 16.52 & 34.13 & 32.81 \\
\hline \multicolumn{5}{|l|}{ Economic sector } \\
\hline Private sector & 69.83 & 70.87 & 95.75 & 95.53 \\
\hline Public sector & 30.17 & 29.13 & 4.25 & 4.47 \\
\hline \multicolumn{5}{|l|}{ Industry } \\
\hline Construction & 19.05 & 18.62 & 22.87 & 22.52 \\
\hline Transport, post and telecommunication services, and storage & 19.58 & 20.72 & - & - \\
\hline Wholesale, retail trade and catering services & 10.32 & 11.11 & 32.08 & 31.45 \\
\hline Health care, sports and social welfare & 13.23 & 12.01 & - & - \\
\hline Other & Omitted & Omitted & Omitted & Omitted \\
\hline \multicolumn{5}{|l|}{ Hukou status } \\
\hline Local residents & 54.07 & 53.75 & 51.86 & 50.68 \\
\hline Migrants & 45.93 & 46.25 & 48.14 & 49.32 \\
\hline \multicolumn{5}{|l|}{ Sex } \\
\hline Female & 41.99 & 41.74 & 47.46 & 50.10 \\
\hline Male & 58.01 & 58.26 & 52.54 & 49.90 \\
\hline
\end{tabular}

precarious workers in Hong Kong are more likely to be found among those with low levels of education-only $7.96 \%$ of them have an associate's degree or higher. Also, in mainland China, 29.13\% of precarious workers work in the public sector, whereas in Hong Kong, 95.53\% of precarious workers work in the private sector. Therefore, although some scholars have pointed out that precarious work in Hong Kong has expanded from the lower end to the higher end of the occupational hierarchy and from the private sector to the public sector (see Chiu et al. 2008; Wu and Li 2013), it is still 
highly concentrated in certain groups, compared to mainland China. This concentration is documented in the official statistics (Ngo 2002), yet, in the absence of cross-societal comparisons, it has largely been overlooked. In contrast, mainland China has witnessed a significant expansion of precarious work in all occupations, which is consistent with other scholars' observations (e.g. Friedman and Lee 2010; Tian 2014).

However, the two cases present considerable similarity in other individual characteristics, such as sex and migration status. In both cases, over $40 \%$ of precarious workers are migrants, and over half are male. Thus, unlike the experience of Western societies, precarious work in Hong Kong and in mainland China is not a "gender-specific phenomenon." Concerning industry, the two cases have both similarities and differences. On the one hand, in both cases, about $20 \%$ of precarious workers work in construction. On the other hand, $31.45 \%$ of precarious workers in Hong Kong work in

Table 2 Incidence rates of precarious work in mainland China and Hong Kong

\begin{tabular}{|c|c|c|c|c|}
\hline & \multicolumn{2}{|c|}{ Mainland China } & \multicolumn{2}{|l|}{ Hong Kong } \\
\hline & Sample size & Incidence rate $(\%)$ & Sample size & Incidence rate (\%) \\
\hline Total analytical sample & 2,413 & 13.80 & 2,812 & 18.31 \\
\hline \multicolumn{5}{|l|}{ Age } \\
\hline$<30$ & 618 & 9.71 & 670 & 15.52 \\
\hline $30+$ & 751 & 11.19 & 627 & 11.96 \\
\hline $40+$ & 698 & 16.76 & 724 & 17.82 \\
\hline $50+$ & 292 & 18.84 & 611 & 25.20 \\
\hline$>=60$ & 54 & 31.48 & 180 & 29.44 \\
\hline \multicolumn{5}{|l|}{ Education } \\
\hline Primary school or lower & 161 & 36.65 & 438 & 34.93 \\
\hline Middle school & 607 & 19.60 & 560 & 29.64 \\
\hline High school & 768 & 11.33 & 1,079 & 14.37 \\
\hline Associate degree & 406 & 7.14 & 214 & 8.88 \\
\hline College degree or higher & 471 & 8.28 & 521 & 4.22 \\
\hline \multicolumn{5}{|l|}{ Occupation } \\
\hline Manager/director & 192 & 12.50 & 212 & 1.89 \\
\hline Professional/technician & 842 & 11.28 & 534 & 5.06 \\
\hline Administrative staff & 446 & 8.07 & 525 & 6.29 \\
\hline Sales and service staff & 492 & 13.21 & 677 & 26.59 \\
\hline Production staff & 237 & 18.57 & 399 & 25.56 \\
\hline Non-skilled labor and other & 204 & 33.82 & 465 & 36.34 \\
\hline \multicolumn{5}{|l|}{ Economic sector } \\
\hline Private sector & 1391 & 16.97 & 2495 & 19.72 \\
\hline Public sector & 1022 & 9.49 & 317 & 7.26 \\
\hline \multicolumn{5}{|l|}{ Hukou status } \\
\hline Local residents & 1547 & 11.57 & 1918 & 13.61 \\
\hline Migrants & 866 & 17.78 & 894 & 28.41 \\
\hline \multicolumn{5}{|l|}{ Sex } \\
\hline Female & 1081 & 12.86 & 1302 & 19.82 \\
\hline Male & 1332 & 14.56 & 1510 & 17.02 \\
\hline Industry & Omitted & Omitted & Omitted & Omitted \\
\hline
\end{tabular}


low-end service sector jobs, such as retailing and food services, while this figure is only $11.11 \%$ in mainland China. This difference may have to do with the different economic structures of the two societies. Hong Kong has gone through a process of deindustrialization since the 1990s, which has led to a surge in the population working in the service sector. By contrast, mainland China has become the world's factory. Existing literature suggests that de-industrialization and the expansion of the low-end service sector are important driving forces behind the expansion of precarious work (Lee and Wong 2004). The comparison between mainland China and Hong Kong supports this argument.

Table 2 presents the incidence rates of precarious work in mainland China and Hong Kong. A comparison of the total analytical samples suggests that the incidence rate of precarious work is slightly higher in Hong Kong (18.31\%) than in mainland China $(13.80 \%){ }^{8}$ Regarding the subsamples in each case, the bivariate relationships between the incidence rate of precarious work and factors such as age, education, occupation, economic sector, and hukou status are quite similar for mainland China and for Hong Kong. Take age as an example: in both cases, the older the respondent, the more likely he or she is to enter precarious employment. In mainland China, for the age groups $30-39,40-49,50-59$ and above 60 , the incidence rates of precarious work are $11.19 \%$, $16.76 \%, 18.84 \%$ and $31.48 \%$, respectively. A chi-squared test shows that this association is statistically significant $(p<0.001)$. In Hong Kong, from the age group 30-39 to the age group 60 and above, the incidence rates of precarious work increased from 11.96 to $29.44 \%$, which is also statistically significant in the chi-squared test $(p<0.001)$. Moreover, in both cases, people with lower levels of education, those working in the private sector, and migrants are more likely to engage in precarious work than those with higher levels of education, those working in the public sector and local residents (this result was also statistically significant in the chi-squared test $[p<0.001])$. Meanwhile, Table 2 also shows that precarious work is an endogenous variable. It is necessary to introduce advanced statistical models to fix this endogeneity problem.

Now let us come back to the core question of this research: is labor market segmentation caused by precarious work more severe in Hong Kong than in mainland China? Table 3 presents the results of our OLS analysis. For mainland China, after controlling for other variables, Model 1 shows that a precarious worker earns a salary that is $13 \%$ lower than a formal employee. Thus, a segmentation in wages exists. However, in Model 2, the interaction term of the "precarious work" and "years of schooling" variables is not statistically significant. Considering the multicollinearity between the interaction term and the "precarious work" variable (their correlation coefficient is as high as 0.95), the author centered the "years of schooling" variable and generated a new interaction term, which is also not statistically significant. This analysis supports the hypothesis that labor market segmentation based on wages exists, but it does not support the hypothesis that the labor market is segmented with respect to return on education.

For Hong Kong, after controlling for other variables, Model 1 shows that a precarious worker earns $41 \%$ less than a formal employee. This number is much larger than that of mainland China. This means that the segmentation of wages is much greater in

${ }^{8}$ Please note that these incidence rates are for reference only. As the definition of "precarious work" in this research only includes three criteria (as mentioned in the previous section), these rates may be underestimated. 
Table 3 Differentials in wages and return on education between precarious workers and nonprecarious workers in mainland China and Hong Kong (OLS)

\begin{tabular}{|c|c|c|c|c|c|c|}
\hline & \multicolumn{3}{|c|}{ Mainland China } & \multicolumn{3}{|c|}{ Hong Kong } \\
\hline & Model 1 & Model 2 & Model 3 & Model 1 & Model 2 & Model 3 \\
\hline Precarious work & $\begin{array}{l}-.134^{* * *} \\
(.039)\end{array}$ & $\begin{array}{l}-.165 \\
(.135)\end{array}$ & $\begin{array}{l}-.130^{* *} \\
(.042)\end{array}$ & $\begin{array}{l}-.524^{* * *} \\
(.029)\end{array}$ & $-.036(.067)$ & $\begin{array}{l}-.613^{* * *} \\
(.031)\end{array}$ \\
\hline Years of schooling & $\begin{array}{l}.073^{* * *} \\
(.006)\end{array}$ & $\begin{array}{l}.073^{* * *} \\
(.006)\end{array}$ & $\begin{array}{l}.073^{* * *} \\
(.006)\end{array}$ & $\begin{array}{l}.044^{* * *} \\
(.003)\end{array}$ & $\begin{array}{l}.056^{* * *} \\
(.004)\end{array}$ & $\begin{array}{l}.056^{* * *} \\
(.004)\end{array}$ \\
\hline $\begin{array}{l}\text { Precarious work } \times \text { years of } \\
\text { schooling }\end{array}$ & - & $.003(.012)$ & $.003(.012)$ & - & $\begin{array}{l}-.052^{* * *} \\
(.006)\end{array}$ & $\begin{array}{l}-.052^{* * *} \\
(.006)\end{array}$ \\
\hline Controls & Yes & Yes & Yes & Yes & Yes & Yes \\
\hline$R^{2}$ & .37 & .37 & .37 & .61 & .62 & .62 \\
\hline$N$ & 2413 & 2413 & 2413 & 2812 & 2812 & 2812 \\
\hline
\end{tabular}

(1) The "years of schooling" variable is not centered in Models 1 and 2, though it is centered in Model 3. (2) Control variables include sex, age, age squared, economic sector, hukou status, occupation, industry, weekly working hours and intercept (the Models for mainland China also include province dummies). (3) The non-standardized regression coefficients are reported, and the numbers in parentheses are standard errors

${ }^{*} p<0.05,{ }^{* *} p<0.01,{ }^{* * *} p<0.001$ (two-tailed test)

Hong Kong than in mainland China. Model 2 demonstrates that the interaction term of the "precarious work" and "years of schooling" variables is also statistically significant $(p<0.001)$, while the correlation coefficient of the interaction term and the "precarious work" variable is 0.92 . Possibly due to multicollinearity, the main effect of the "precarious work" variable is not significant. After centering the "years of schooling" variable, both the main effect and the interaction effect become significant. Model 2 and Model 3 suggest that, compared to formal employees, precarious workers not only earn significantly lower wages (the main effect is negative), but also expect significantly lower returns on education (the interaction effect is negative). Take Model 2 as an example: for a formal employee, each extra year of schooling is associated with a 5.8\% increase in his or her income. By contrast, this figure is only $0.4 \%$ for precarious workers. Thus, the labor market in Hong Kong is segmented in both wages and the return on education.

Because OLS estimation can be biased, the author used a propensity score analysis and switching regression to further test whether the segmentation of wages and return on education exist. In Table 4, no matter whether we use the method of propensity score weighting or propensity score matching, ${ }^{9}$ for both mainland China and Hong Kong, precarious workers earn significantly lower wages than their peers in the formal

Table 4 Wage differential between precarious workers and non-precarious workers in mainland China and Hong Kong (propensity score analysis)

\begin{tabular}{|c|c|c|c|c|}
\hline & \multicolumn{2}{|l|}{ Mainland China } & \multicolumn{2}{|l|}{ Hong Kong } \\
\hline & $\begin{array}{l}\text { Propensity score } \\
\text { weighting }\end{array}$ & $\begin{array}{l}\text { Propensity score } \\
\text { matching }\end{array}$ & $\begin{array}{l}\text { Propensity score } \\
\text { weighting }\end{array}$ & $\begin{array}{l}\text { Propensity score } \\
\text { matching }\end{array}$ \\
\hline Precarious work & $-.141^{* *}(.044)$ & $-.117^{*}(.055)$ & $-.461^{* * *}(.042)$ & $-.399 * * *(.040)$ \\
\hline Controls & Yes & Yes & Yes & Yes \\
\hline$R^{2}$ & .39 & .42 & .63 & .55 \\
\hline$N$ & 2413 & 662 & 2812 & 1021 \\
\hline
\end{tabular}


Table 5 Differential in return on education between precarious workers and non-precarious workers in mainland China and Hong Kong (switching regression)

\begin{tabular}{llllll}
\hline & Mainland China & & & Hong Kong \\
\cline { 2 - 3 } & Non-precarious work & Precarious work & & Non-precarious work & Precarious work \\
\hline Years of schooling & $.071^{* * *}(.006)$ & $.048^{*}(.021)$ & & $.061^{* * *}(.003)$ & $.015(.011)$ \\
Controls & Yes & Yes & & Yes & Yes \\
$\mathrm{N}$ & 2413 & & 2812 & \\
\hline
\end{tabular}

(1) For the list of control variables, please refer to the note in Table 3. (2) The non-standardized regression coefficients are reported, and the numbers in parentheses are standard errors. (3) The results of the choice model are not shown in the Table

${ }^{*} p<0.05,{ }^{* *} p<0.01,{ }^{* * *} p<0.001$ (two-tailed test)

sector, and the absolute value of the new estimated coefficient is greater for Hong Kong than for mainland China. For example, after being weighted by the propensity score, the estimation is -0.141 for mainland China, and -0.461 for Hong Kong. This suggests that the segmentation in wages is deeper in Hong Kong. The author also conducted a Blinder-Oaxaca decomposition (Blinder 1973) and found that while only $36.18 \%$ of the differential is unexplained for mainland China, this figure is $53.13 \%$ for Hong Kong. This also supports the conclusion that precarious workers in Hong Kong face greater discrimination and deeper segmentation in wages.

The switching regression analysis in Table 5 also suggests that, in the return on education, the gap between precarious workers and formal employees is smaller in mainland China than in Hong Kong. For mainland China, the coefficient of the "years of schooling" variable is 0.07 for formal employees and 0.05 for precarious workers (a differential of 0.02 units). For Hong Kong, this coefficient is 0.06 for formal employees and 0.02 for precarious workers (a differential of 0.04 units); moreover, the "years of schooling" variable for precarious workers is not even statistically significant, suggesting that human capital does not have an impact on this segment of the labor market. This is highly consistent with the classical labor market segmentation theory. In conclusion, Hong Kong is characterized by deeper labor market segmentation in return on education between precarious workers and non-precarious workers, in comparison with mainland China.

Mainland China is highly heterogeneous given its expansive territory. Although in this research only urban samples are used and dummy variables from provinces are controlled, its comparability with the case of Hong Kong remains a concern. For this reason, the author conducted two additional comparisons with the HKPSSD data. For the first comparison, the author created a subsample of major cities (including largeand medium-sized cities as well as economically developed cities in the coastal region, including Shanghai) out of the CLDS data. For the second comparison, the SUNS data are used. The results are shown in Table 6. Regarding wages, no matter which method is used, precarious workers earn significantly less than formal employees in all three datasets, and this gap is greater in Hong Kong than in mainland China. As for return on education, no matter which method is used, in Hong Kong, return on education is significantly lower for precarious workers than for formal employees, but it is not

\footnotetext{
${ }^{9}$ More specifically, in propensity score weighting, we run a weighted regression using propensity scores. In propensity score matching, we did a one-on-one greedy match according to the propensity scores. In either method, propensity scores are predicted by variables including sex, age, level of education, occupation, economic sector, and hukou status.

${ }^{10}$ The results based on the CLDS subsample (major cities) data are not presented in Tables 3 and 4, as they are quite similar to the results based on the CLDS full sample data.
} 
Table 6 Differentials in wages and return on education between precarious workers and nonprecarious workers in mainland China and Hong Kong (robustness check)

\begin{tabular}{|c|c|c|c|c|c|c|}
\hline & \multicolumn{2}{|c|}{$\begin{array}{l}\text { CLDS subsample of } \\
\text { major cities }\end{array}$} & \multicolumn{2}{|l|}{ SUNS } & \multicolumn{2}{|l|}{ HKPSSD } \\
\hline & $\begin{array}{l}\text { Non-precarious } \\
\text { work }\end{array}$ & $\begin{array}{l}\text { Precarious } \\
\text { work }\end{array}$ & $\begin{array}{l}\text { Non-precarious } \\
\text { work }\end{array}$ & $\begin{array}{l}\text { Precarious } \\
\text { work }\end{array}$ & $\begin{array}{l}\text { Non-precarious } \\
\text { work }\end{array}$ & $\begin{array}{l}\text { Precarious } \\
\text { work }\end{array}$ \\
\hline $\begin{array}{l}\text { Wage differential } \\
(\mathrm{OLS})\end{array}$ & - & $-.134^{* *}(.047)$ & - & $-.264^{* * *}(.047)$ & - & $-.524^{* * *}(.029)$ \\
\hline $\begin{array}{l}\text { Wage differential } \\
\text { (propensity score } \\
\text { weighting) }\end{array}$ & - & $-.109^{*}(.051)$ & - & $-.260^{* *}(.081)$ & - & $-.461^{* * *}(.042)$ \\
\hline $\begin{array}{l}\text { Wage differential } \\
\text { (propensity score } \\
\text { matching) }\end{array}$ & - & $-.139 *(.065)$ & - & $-.271^{* * *}(.076)$ & - & $-.399^{* * *}(.040)$ \\
\hline $\begin{array}{l}\text { Differential of } \\
\text { return on } \\
\text { education (OLS) }\end{array}$ & - & $.003(.012)$ & - & $-.017(.011)$ & - & $-.052^{* * *}(.006)$ \\
\hline $\begin{array}{l}\text { Differential of } \\
\text { return on education } \\
\text { (switching regression) }\end{array}$ & $.075^{* * *}(.007)$ & $.059^{*}(.027)$ & $.062^{* * *}(.005)$ & $.067^{* *}(.021)$ & $.061^{* * *}(.003)$ & $.015(.011)$ \\
\hline
\end{tabular}

(1) For the list of control variables, please refer to the note in Table 3. (2) The non-standardized regression coefficients are reported, and the numbers in parentheses are standard errors. (3) Regarding the subsample of the CLDS data, "major cities" refers to large- and medium-sized cities, as well as economically developed cities in the coastal region, including direct-administered municipalities, sub-provincial municipalities, provincial capitals and cities with a high GDP per capita in the coastal provinces. The analytical sample size is 1846 persons. (4) The analytical sample size of the SUNS data is 4366 persons. (5) ${ }^{*} p<0.05,{ }^{* *} p<0.01,{ }^{* * *} p<0.001$ (two-tailed test)

statistically significant in mainland China. This is highly consistent with the results in Tables 3, 4 and 5.

The analyses in Tables 3, 4, 5 and 6 still have two limitations. First, wage averages are analyzed in the models, which only reflect the overall situation of the two groups and overlooks the income distribution within each group. In other words, for people from different income groups, the effect of precarious work or formal employment on wages and return on education may be different. To address the issue of heterogeneity, I performed quantile regressions with the three datasets and obtained the main effect coefficients (the effect of precarious work on wages) and the interaction coefficients (the interaction of precarious work and years of schooling) for all percentiles, as depicted in Figs. 3 and $4 .{ }^{10}$ Figure 3 shows that the negative effect of precarious work on wages decreases as wages increase. This suggests that the wage gap between formal employees and precarious workers is greater in lower income groups, and smaller in higher income groups. Despite such heterogeneity, a comparison of Hong Kong and mainland China (including Shanghai) shows that, for all wage quantiles, the wage gap between precarious and non-precarious work is greater in Hong Kong than in mainland China. As Fig. 4 shows, the patterns of how precarious work moderates the return on education in each wage quantile vary considerably among the three datasets. In the CLDS dataset, the moderating effect changes from positive to negative. In the SUNS dataset, the moderating effect stays negative, and the effect becomes slightly smaller at higher wage quantiles. In the HKPSSD dataset, the moderating effect of precarious work not only stays negative, but its magnitude remains fairly unchanged. Nevertheless, despite this variation, for all percentiles, the moderating effect of precarious work on the return

\footnotetext{
${ }^{11}$ The nominal income data of mainland China (including Shanghai) and of Hong Kong are not comparable. Thus, in this article, they are adjusted using the 2012 PPP conversion factor published by the World Bank. For the method of conversion, please refer to the official website of the World Bank:https://data.worldbank. org.cn/indicator/PA.NUS.PPP?\%20emd=2011\&start=1990\&view=chart.
} 


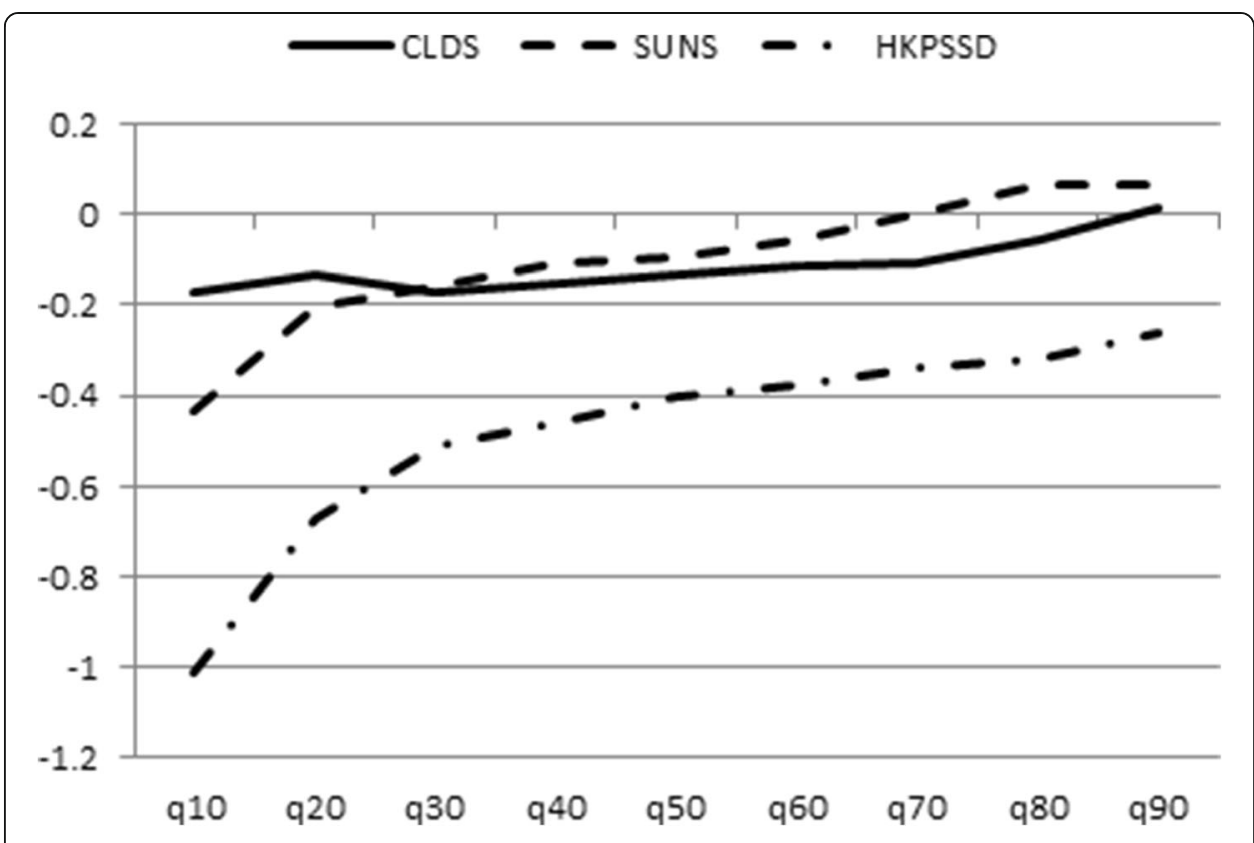

Fig. 3 Wage differentials between precarious workers and non-precarious workers (quantile regressions)

on education is greater in Hong Kong than in mainland China (including Shanghai). In sum, the quantile regression results in Figs. 3 and 4 demonstrate that, although heterogeneity can be identified in both cases, the degree of labor market segmentation differs systematically between mainland China and Hong Kong. This is also consistent with the results of previous regressions that use group means.

Second, the models in Tables 3, 4, 5 and 6 analyze the cases of mainland China (including Shanghai) and Hong Kong separately, instead of directly examining the

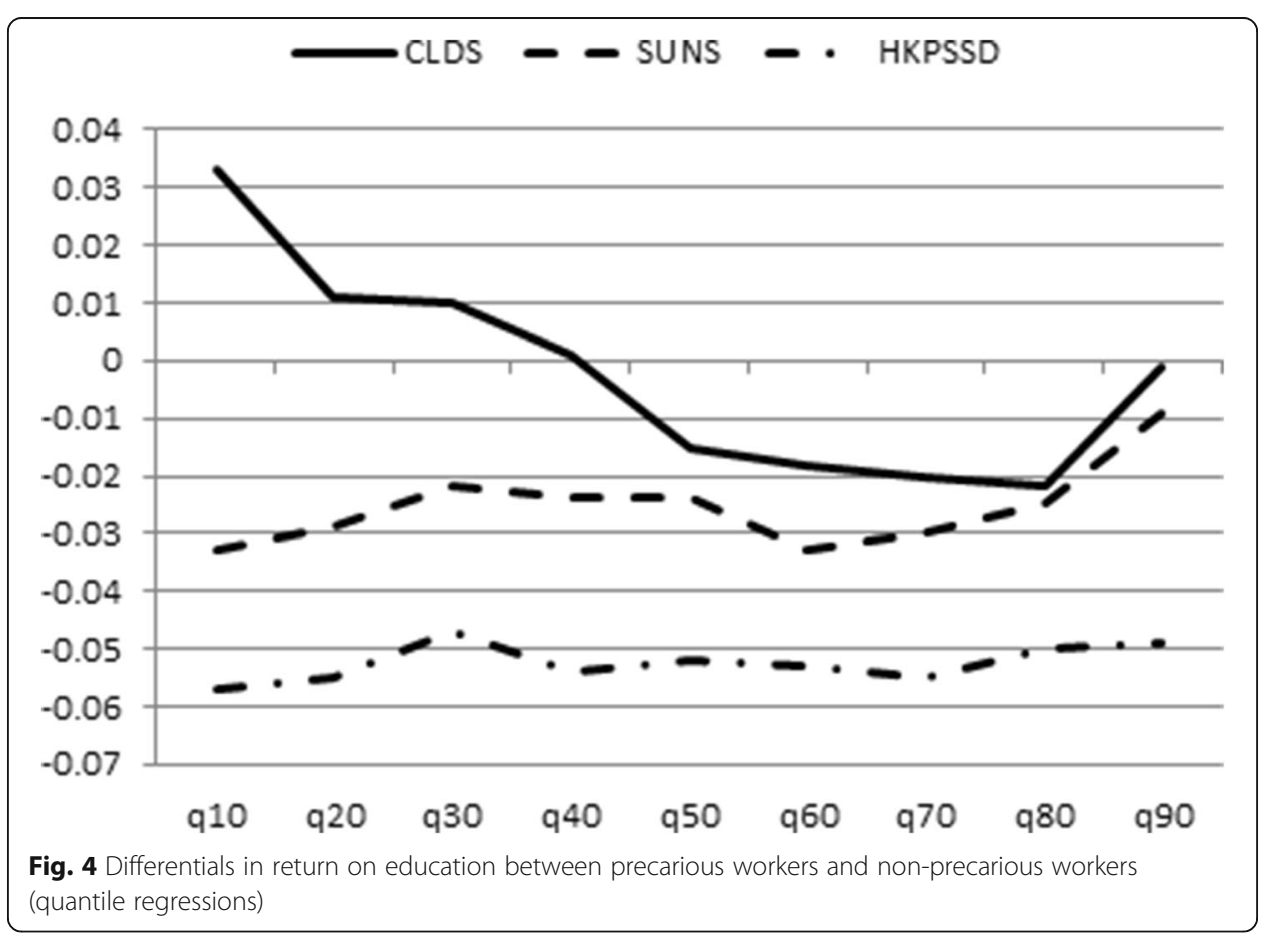




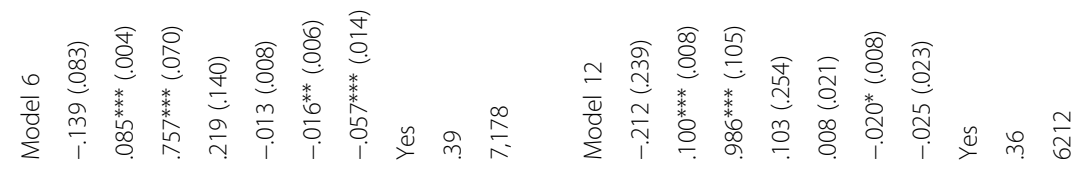

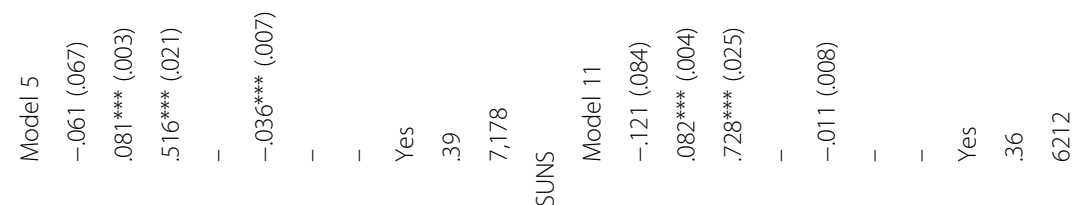

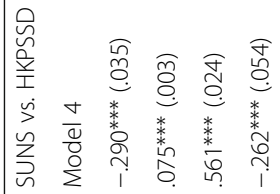

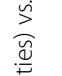

离

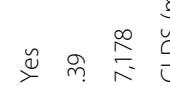

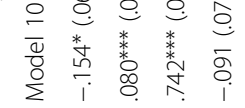

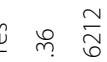

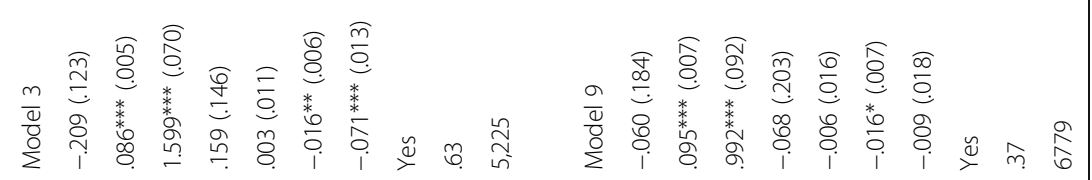

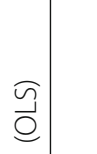

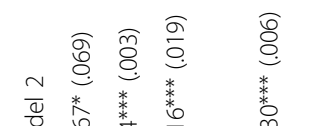

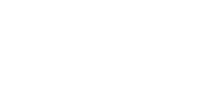

更

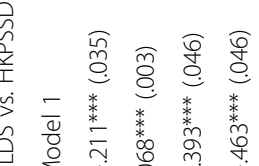

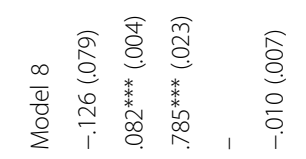

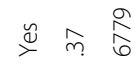

ขึ

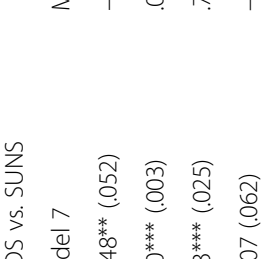

$\stackrel{\vartheta}{\approx} \stackrel{\overbrace{}}{\approx}$

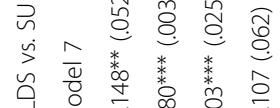
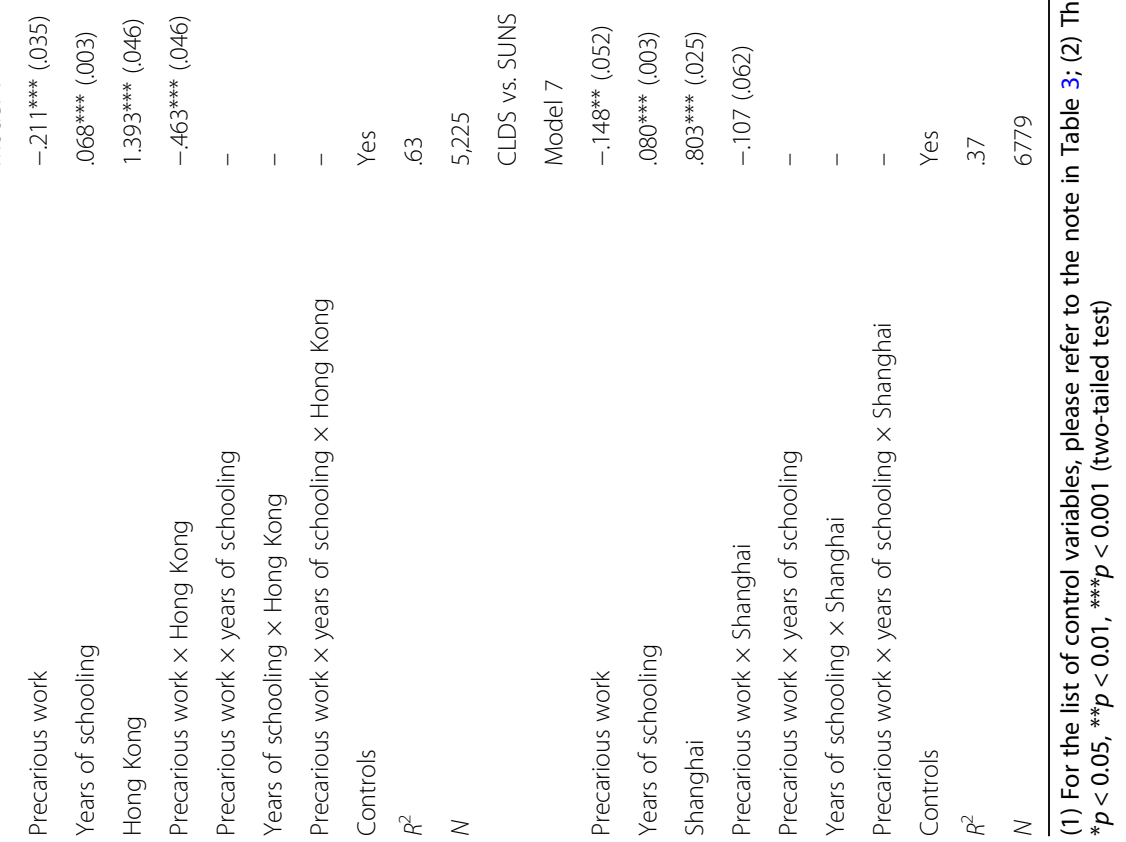
differences between the two cases. To address this issue, the author combined the datasets together to reexamine two propositions: (1) the wage gap between precarious and non-precarious work is greater in Hong Kong than in mainland China (including Shanghai) and (2) the negative moderating effect of precarious work on the return on education is greater in Hong Kong than in mainland China (including Shanghai). ${ }^{11}$ Meanwhile, in order to further examine the key logic proposed in this research-i.e., the institutional difference is the reason why labor market segmentation is deeper in Hong Kong than in mainland China-two further predictions are made: (3) the wage gap between precarious and non-precarious work does not differ significantly between the CLDS (and its subsample of major cities) data and the SUNS data; and (4) the negative moderating effect of precarious work on return on education does not vary significantly between the CLDS (and its subsample of major cities) data and the SUNS data. The author merged and compared this data accordingly, and the results are shown in Table 7.

The upper panel of Table 7 compares (1) the CLDS data and the HKPSSD data and (2) the SUNS data and the HKPSSD data. In Models 1 and 4, the main effect of precarious work on wages is significantly negative, and the interaction term of the "precarious work" and "Hong Kong" variables is also significantly negative. Thus, proposition (1) is supported. In Models 2 and 5, the coefficient of the "years of schooling" variable is significantly positive, and the interaction term of the "precarious work" and "years of schooling" variables is significantly negative. Thus, precarious work has a negative moderating effect on return on education. In Models 3 and 6, the interaction term of the "precarious work," "years of schooling," and "Hong Kong" variables is added, and it is also significantly negative. This means that the negative moderating effect of precarious work on the return on education is greater in Hong Kong than in mainland China, which supports proposition (2).

The lower panel of Table 7 compares (1) the CLDS data and the SUNS data, and (2) the CLDS subsample of major cities and the SUNS data. Models 7 and 10 show that the interaction term of the "precarious work" and "Shanghai" variables is not statistically significant, which supports prediction (3). In Models 8 and 11, the interaction term of the "precarious work" and "years of schooling" variables is not significant. In Models 9 and 12, the interaction term of the "precarious work," "years of schooling" and "Shanghai" variables is not significant either. Thus, prediction (4) is supported.

\section{Conclusions and discussion}

Against the backdrop of "one country, two systems", precarious work has expanded rapidly in both mainland China and Hong Kong, which provides two ideal subjects for cross-societal comparative research. The key research question in this article is: regarding whether precarious work has created labor market segmentation, is there any difference between mainland China and Hong Kong due to their different social and economic systems? In Hong Kong, as the result of its liberal economic policies, the government hardly intervenes in labor relations, whereas in mainland China, labor regulations have been tightened and loosened in alternating succession. The key hypothesis proposed here is that precarious workers in Hong Kong face deeper labor market segmentation than their counterparts in mainland China. 
Empirically, this segmentation is manifested by two forms: differentials in wages and return on education between precarious workers and non-precarious workers. The analysis of survey data from the two societies supports the key hypothesis in this article. Regarding wages, precarious work causes labor market segmentation in both societies. Yet, this segmentation is deeper in Hong Kong, suggesting that precarious workers in Hong Kong suffer greater wage loss or wage discrimination compared to their counterparts in mainland China. As for return on education, precarious work causes segmentation in Hong Kong (and the effect is notable), but the effect is insignificant or minimal in mainland China. Even when we compare Shanghai with Hong Kong, the same conclusion still holds. On the contrary, no significant difference is identified when data from mainland China are compared to data from Shanghai. Therefore, it is the varying regulatory norms and practices in the labor markets in mainland China and Hong Kong that lead to the different degrees of labor market segmentation.

The expansion of nonstandard labor relations and precarious work has been a global phenomenon since the end of the twentieth century. Previous research in the USA, UK and Continental Europe, as well as this article (on mainland China and Hong Kong) concur that precarious work causes a new form of labor market segmentation. While drawing a cross-societal comparison, this article further points out that, to a certain extent, government intervention in labor legislation and labor relations can also affect the degree of this new labor market segmentation. In other words, even though the "new economy" has inevitably led to nonstandard labor relations and job instability, the government can still mitigate negative impacts on labor by implementing labor laws and regulations. This viewpoint coincides with the position taken by earlier theorists who conducted comparative research on this topic in the USA, Japan and Europe (e.g. Gottfried 1995).

The research on precarious work and labor market segmentation in this article has two major limitations due to data limitations. The first is the heterogeneity within the group of precarious workers. As the sample size is small, it is impossible to classify precarious workers into subgroups and make comparisons. Second, due to a lack of longitudinal data, this research is unable to respond to the question of whether precarious work is a "bridge" or a "trap" for workers. Moreover, precarious work may lead to consequences in other social spheres, such as a hesitation to invest in education, a low willingness to marry, a low willingness to volunteer (Kalleberg 2009). This issue has also been politicized to a certain extent in different regions of the world, including the Middle-East, Southern Africa, Western Europe, and in the USA (Lee and Kofman 2012). More research should be carried out in the future to address these important issues.

Abbreviations

CLDS: China Labor Force Dynamics Survey; HKPSSD: Hong Kong Panel Study of Social Dynamics; SUNS: Shanghai Urban Neighborhood Survey

\section{Acknowledgements}

The author does this research and writes this manuscript by himself.

Authors' contributions

There is only one author in this research, and he contributes all to this manuscript. The author read and approved the final manuscript. 


\section{Availability of data and materials}

One can apply for the three data sets used in this article by contacting the corresponding research centers in three universities. For the China Labor Force Dynamics Survey (CLDS), please contact the Center for Social Survey, Sun YatSen University. For the Shanghai Urban Neighborhood Survey (SUNS), please contact the Center for Data and Urban Science, Shanghai University. For the Hong Kong Panel Study of Social Dynamics (HKPSSD), please contact the Center for Applied Social and Economic Research, Hong Kong University of Science and Technology.

\section{Competing interests}

The author declares that he has no competing interests.

Received: 21 April 2019 Accepted: 8 July 2019

Published online: 06 August 2019

\section{References}

Atkinson, John. 1984. Manpower strategies for flexible organisations. Personnel Management 16 (8): 28-31.

Atkinson, John. 1987. Flexibility or fragmentation? The United Kingdom labour market in the eighties. Labour and Society 12 (1): 87-105.

Baron, James N., and William T. Bielby. 1980. Bringing the firms back in: stratification, segmentation, and the organization of work. American Sociological Review 45 (5): 737-765.

Blinder, Alan S. 1973. Wage discrimination: reduced form and structural estimates. Journal of Human Resources 8 (4): $436-455$.

Cai, Fang. 2004. Consistency of China's statistics on employment: stylized facts and implications for public policies. Chinese Journal of Population Science 3: 2-10 (in Chinese).

Center for Social Survey in Sun Yat-Sen University. 2013. Report on China Labor-force Dynamic Survey (2013). Beijing: Social Sciences Academic Press (in Chinese).

Chang, Jinxiong, and Danfeng Wang. 2010. Wage differentials between formal and informal employment in China's urban labor market. The Journal of Quantitative \& Technical Economics 27 (9): 94-106 (in Chinese).

Chiu, Stephen W.K., Alvin Y. So, and May Yeuk-mui Tam. 2008. Flexible employment in Hong Kong: trends and patterns in comparative perspective. Asian Survey 48 (4): 673-702.

Doeringer, Peter B., and Michael J. Piore. 1971. Internal labor markets and manpower analysis. Lexinton: D. C. Heath.

Dong, Baohua. 2007. Labor dispatch. Beijing: China Human Resources \& Social Security Press (in Chinese).

Friedman, Eli, and Ching Kwan Lee. 2010. Remaking the world of Chinese labour: a 30-year retrospective. British Journal of Industrial Relations 48 (3): 507-533.

Gash, Vanessa. 2008. Bridge or trap? Temporary workers' transitions to unemployment and to the standard employment contract. European Sociological Review 24 (5): 651-668.

Gash, Vanessa, and Frances McGinnity. 2007. Fixed-term contracts - the New European inequality? Comparing men and women in West Germany and France. Socio-Economic Review 5 (3): 467-496.

Ge, Suqin. 2000. Recent advance in the theory of labor market segmentation. Economic Perspectives 12: $53-56$ (in Chinese).

Giesecke, Johannes. 2009. Socio-economic risks of atypical employment relationships: evidence from the German labour market. European Sociological Review 25 (6): 629-646.

Giesecke, Johannes, and Martin Groß. 2003. Temporary employment: chance or risk? European Sociological Review 19 (2): $161-177$. Gottfried, Heidi. 1995. Developing Neo-Fordism: a comparative perspective. Critical Sociology 21 (3): 39-70.

Guo, Shenyang, and Mark W. Fraser. 2010. Propensity score analysis: statistical methods and applications. Thousand Oaks: Sage Publications.

Harrison, Bennett. 1994. Lean and mean: The changing landscape of corporate power in the age of flexibility. New York: Basic Books.

Huang, Qian. 2009. Job stability and its effect on wages among migrant workers in the city. Population Research 33 (3): 53-62 (in Chinese).

Hudson, Kenneth. 2007. The new labor market segmentation: labor market dualism in the new economy. Social Science Research 36 (1): 286-312.

Jacobs, Jerry A., and Zhenchao Qian. 1997. The mobility patterns of part-time workers. Research in Social Stratification and Mobility 15: 29-56.

Kalleberg, Arne L. 2000. Nonstandard employment relations: part-time, temporary and contract work. Annual Review of Sociology 26 (1): 341-365.

Kalleberg, Arne L. 2003. Flexible firms and labor market segmentation: effects of workplace restructuring on jobs and workers Work and Occupations 30 (2): 154-175.

Kalleberg, Arne L. 2009. Precarious work, insecure workers: employment relations in transition. American Sociological Review $74(1): 1-22$.

Kalleberg, Arne L., and Kevin Hewison. 2013. Precarious work and the challenge for Asia. American Behavioral Scientist 57 (3): $271-288$.

Kalleberg, Arne L., Barbara F. Reskin, and Ken Hudson. 2000. Bad jobs in America: standard and nonstandard employment relations and job quality in the United States. American Sociological Review 65 (2): 256-278.

Kalleberg, Arne L., and Aage B. Sorensen. 1979. The sociology of labor markets. Annual Review of Sociology 5 (1): $351-379$

Kou, Enhui, and Baihui Liu. 2013. The stable employment of rural migrants and the wage gap in urbanization based on quantile regression. The Journal of Quantitative \& Technical Economics 30 (7): 3-19 (in Chinese).

Lee, Ching Kwan, and Yelizavetta Kofman. 2012. The politics of precarity: views beyond the United States. Work and Occupations 39 (4): 388-408.

Lee, Kim Ming, and Hung Wong. 2004. Marginalized workers in postindustrial Hong Kong. The Journal of Comparative Asian Development 3 (2): 249-280.

Li, Jun. 2016. Urban labor market segmentation in China: an analysis of integration and comparation. Jianghai Academic Journal 3: 103-110 (in Chinese).

Li, Lingyun. 2011. The legislation made by international labor organization on labor force dispatching. Labour Union Studies 3 : 1-4 (in Chinese). 
Li, Xiaoying, and Zhong Zhao. 2016. New trend of China's urban labor market segmentation and income gap based on employment contract perspective. Journal of Beijing Technology and Business University (Social Sciences) 2: 10-20 (in (hinese).

Luo, Chuliang. 2008. Job stability and labor earning inequality. Chinese Journal of Population Science 4: 11-21 (in Chinese).

Mansson, Jonas, and Jan Ottosson. 2011. Transitions from part-time unemployment: is part-time work a dead end or a stepping stone to the labour market? Economic and Industrial Democracy 32 (4): 569-589.

McGinnity, Frances, Antje Mertens, and Stefanie Gundert. 2005. A bad start? Fixed-term contracts and the transition from education to work in West Germany. European Sociological Review 21 (4): 359-374.

McGovern, Patrick, Deborah Smeaton, and Stephen Hill. 2004. Bad jobs in Britain: nonstandard employment and job quality. Work and Occupations 31 (2): 225-249.

Ngo, Hang-Yue. 2002. Part-time employment in Hong Kong: a gendered phenomenon? International Journal of Human Resource Management 13 (2): 361-377.

O'Connor, Julia S. 2013. Non-standard employment and European Union employment regulation. In Non-standard employment in Europe: paradigms, prevalence and policy responses, ed. Max Koch and Martin Fritz, 46-63. London: Palgrave Macmillan.

Park, Albert, and Fang Cai. 2011. The informalization of the Chinese labor market. In From Iron Rice Bowl to informalization: markets, workers, and the state in a changing China, ed. Sarosh Kuruvilla, Ching Kwan Lee, and Mary E. Gallagher, 17-35. Ithaca: ILR Press.

Pedulla, David S. 2016. Penalized or protected? Gender and the consequences of nonstandard and mismatched employment histories. American Sociological Review 81 (2): 262-289.

Peng, Xizhe, and Yu Yao. 2004. To clarify the concept of informal employment and to promote the development of informal employment. Journal of Social Sciences 7: 63-72 (in Chinese).

Polanyi, Karl. 1944. The great transformation: the political and economic origins of our time. New York: Parrar and Rinehart, Inc.

Qu, Xiaobo. 2011. Income gap between formal and informal employment and its influencing factors: a decomposing analysis of income inequality. Collected Essays on Finance and Economics 2: 3-8 (in Chinese).

Qu, Xiaobo. 2012. Wage gap between formal employment and informal employment: based on income inequality decomposition of informal heterogeneity. South China Journal of Economics 30 (4): 32-42 (in Chinese).

Sakamoto, Arthur. 1991. Inequality and attainment in a dual labor market. American Sociological Review 56 (3): 295-308.

Sakamoto, Arthur, and Meichu D. Chen. 1991. Sample selection and the dual labor market. Research in Social Stratification and Mobility 10: 171-198.

Steijn, Bram, Ariana Need, and Maurice Gesthuizen. 2006. Well begun, half done? Long-term effects of labour market entry in the Netherlands, 1950-2000. Work, Employment and Society 20 (3): 453-472.

Sun et al. 2018. Social Pulse of Chinese Metropolis: Shanghai Survey (2017). Beijing: Social Sciences Academic Press (in Chinese).

Swider, Sarah. 2015. Building China: precarious employment among migrant construction workers. Work, Employment and Society 29 (1): 41-59.

Tian, Ye. 2014. Research on legislation and regulations on atypical labor relations. Beijing: China University of Political Science and Law Press (in Chinese).

Wei, Xiahai, and Lingzheng Yu. 2012. Wage differentials between formal and informal employment in urban China: evidence from quantile regression and decomposition. The Journal of Quantitative \& Technical Economics 29 (1): 78-90 (in Chinese).

Wong, May M. 2001. The strategic use of contingent workers in Hong Kong's economic upheaval. Human Resource Management Journal 11 (4): 22-37.

Wu, Xiaogang. 2014. Hong Kong panel study of social dynamics: research designs and preliminary findings. Hong Kong and Macao Journal 4: 62-73 (in Chinese).

Wu, Xiaogang, and Jun Li. 2013. The problem of employment marginalization in Hong Kong: current situation and trends. Bauhinia Forum 4: $58-65$ (in Chinese).

Wu, Yaowu. 2009. The destination of informal employment. Economic Research Journal 44 (7): 91-106 (in Chinese).

Wu, Yaowu, and Fang Cai. 2006. Informal employment in urban China: size and characteristics. China Labor Economics 2: 6784 (in Chinese).

Xiong, Yihan. 2015. Global panorama of the new poor: how is the intersection of the three worlds possible? Beijing Cultural Review 1: 20-25 (in Chinese).

Xue, Jinjun, and Wenshu Gao. 2012. The informal employment in urban China: size, features and earning disparity. Comparative Social and Economic Systems 6: 59-69 (in Chinese).

Yang, Fan. 2015. Wage differentials between formal and informal employment of migrant workers: based on propensity score analysis. Population Research 39 (6): 94-104 (in Chinese).

Yao, Xianguo, and Xu Li. 2005. Labor market segmentation: a review article. Journal of Bohai University (Philosophy \& Social Science Edition) 27 (1): 78-83 (in Chinese).

Yuan, Zhigang. 2008. Is the labor market segmented? Literature review on the empirical studies of "Labor Market Segmentation.". Journal of Yunnan University of Finance and Economics 5: 25-32 (in Chinese).

Zhang, Lu. 2011. The paradox of labor force dualism and state-labor-capital relations in the Chinese automobile industry. In From iron rice bowl to informalization: markets, workers, and the state in a changing China, ed. Sarosh Kuruvilla, Ching Kwan Lee, and Mary E. Gallagher, 103-137. Ithaca: ILR Press.

\section{Publisher's Note}

Springer Nature remains neutral with regard to jurisdictional claims in published maps and institutional affiliations. 